\title{
Erratum to: Chronic adult primary immune thrombocytopenia (ITP) in the Asia-Pacific region
}

\author{
Lai Heng Lee $\cdot$ Priscilla Caguioa $\cdot \mathrm{Ng}$ Soo Chin $\cdot$ \\ Tzeon-Jye Chiou • Jong Wook Lee $\cdot$ Yoshitaka Miyakawa \\ Karmel L. Tambunan $\cdot$ Beng H. Chong
}

Published online: 13 November 2013

(C) The Japanese Society of Hematology 2013

\section{Erratum to: Int J Hematol (2011) 94:142-149 \\ DOI 10.1007/s12185-011-0894-8}

The correct name of the first author should be "L. H. Lee", and not "L. L. Heng" in the affiliations as given in the original publication of the article.

The online version of the original article can be found under doi: 10.1007/s12185-011-0894-8.

\section{H. Lee}

Singapore General Hospital, Singapore, Singapore

P. Caguioa

University of Stanto Tomas Hospital, Manila, Philippines

\section{N. S. Chin}

Sime Darby Medical Centre, Subang Jaya, Malaysia

T.-J. Chiou

Taipei Veterans General Hospital,

National Young-Ming University School of Medicine,

National Defense Medical Center, Taipei, Taiwan

T.-J. Chiou

Hematology Society of Taiwan, Taipei, Taiwan
J. W. Lee

The Catholic University of Korea,

Seoul St. Mary's Hospital, Seoul, Korea

Y. Miyakawa

Keio University, Tokyo, Japan

K. L. Tambunan

University of Indonesia, Jakarta, Indonesia

B. H. Chong $(\bowtie)$

St George Clinical School, University of New South Wales,

St George Hospital, Level 2 Pitney Building,

Belgrave Street, Kogarah, Sydney, NSW 2217, Australia

e-mail: beng.chong@unsw.edu.au 